\title{
APORTACIONES A LA DIAGNOSIS TERRITORIAL DE MENORCA. COMPARACIÓN CON LAS DIRECTRICES DEL PLAN TERRITORIAL INSULAR (2003).
}

\author{
Aina González Puig \\ Ent Environment and Management. \\ David Carreras Martí \\ Observatori Socioambiental de Menorca. \\ Institut Menorquí d'Estudis.
}

Remisión artículo: 26-05-08

Remisión definitiva: 9-06-08

Palabras Clave: Menorca, Plan Territorial Insular, Cartografía digital de Usos y Cubiertas del Suelo, Reserva de la Biosfera.

Resumen: La Cartografía Digital de Usos y Cubiertas del Suelo 1:5.000 se publicó en el 2007 y proporciona información actualizada y en detalle de la situación territorial de la isla. En base a esta cartografía se han analizado los aspectos naturales (análisis de las cubiertas del suelo, conectividad y fragmentación del territorio, estructura y diversidad del paisaje) y los aspectos artificiales o humanizados (usos del suelo, ocupación urbana y áreas de influencia, infraestructuras, urbanización litoral y presión difusa en el medio rural) de los tres municipios más orientales de la isla: Maó, Es Castell y Sant Lluís. La información y la cartografía resultante se han comparado con la cartografía de ordenación y la normativa del Plan Territorial Insular para esta zona, detectando oportunidades de mejora en la clasificación del suelo de algunas áreas y en aspectos cualitativos.

\section{Introducción}

El Plan Territorial Insular de Menorca (PTI) constituye la figura de ordenación territorial básica de Menorca. A pesar de tener carácter derivado, y por tanto estar supeditado a las directrices de normativas de rango superior (p.e. las Directrices de Ordenación Territorial o DOT, aprobadas por el Govern Balear) su amplia capacidad normativa y la escala insular le confieren una gran relevancia para una gestión territorial sostenible.

EI PTI fue aprobado en el año 2003 y elaborado desde el año 1999 al año 2002. Una de las herramientas clave para elaborar el PTI fue la cartografía digital cedida por el Institut Menorquí d'Estudis (IME), a escala 1:25.000 y basada en ortofotografías de 1995. El sistema de clasificación de usos y cubiertas del suelo utilizado se correspondía con la propuesta por el programa europeo CORINE Land Cover $^{1}$, que en su nivel 3 de la leyenda comprende un total de 44 categorías, de las que sólo se describieron las 22 presentes en Menorca. El análisis con Sistemas de Información Geográfica permitió un avance cualitativo tanto en el tratamiento de la información como en la generación de cartografía.

Por otro lado, el Observatorio Socioambiental de Menorca -organismo dedicado al estudio de los parámetros de sostenibilidad de la isla desde la declaración de esta como Reserva de la

\footnotetext{
${ }^{1}$ Directiva 92/43/EEC del Consejo, de 21 de mayo, relativa a la Conservación de los Hábitats Naturales y de la Fauna y la Flora Silvestres.
} 
Biosfera por la UNESCO en el año 1993- publicó en el 2007 la Cartografía digital de Usos y Cubiertas del Suelo, a una escala 1:5.000. Esta cartografía se elaboró en base a ortofotografías del 2002 y a un exhaustivo trabajo de campo realizado entre los años 2002 y $2007^{2}$. Se clasificaron las cubiertas del suelo en 53 categorías, definiendo un nuevo nivel de clasificación respecto al CORINE Land Cover.

Esta nueva cartografía permite un nivel de detalle muy superior, además de ofrecer datos territoriales actualizados, que la que se utilizó inicialmente para la elaboración del PTI. EI análisis de esta cartografía ha constituido el elemento básico que ha permitido evaluar tanto los aspectos naturales (cubiertas del suelo, estructura y diversidad del paisaje, conectividad y fragmentación del territorio) y los antropogénicos (usos del suelo, ocupación urbana y áreas de influencia, infraestructuras, urbanización litoral y presión difusa en el medio rural) de los municipios del levante menorquín.

La información generada a partir de este análisis se ha comparado con las directrices del PTI para la zona de estudio. Por una parte se han comparado los objetivos y su plasmación en la Normativa, y por otra se ha analizado la cartografía digital del planeamiento con aquella generada durante las fases de análisis.

\section{Localización y principales características del Levante menorquín}

Los límites administrativos de los municipios de Maó, Es Castell y Sant Lluís configuran la zona más oriental de la isla de Menorca. Esta zona está experimentando en los últimos años uno de los procesos de transformación territorial más dinámicos de la isla, presentando desde este punto de vista una elevada complejidad. La proximidad de la capital de Menorca, Maó, junto con la diversidad de sistemas paisajísticos y ecológicos que engloba (costero, rural, urbano, boscoso, etc.) le proporcionan estas características.

\subsection{Localización y principales características socio-económicas y ambientales de Menorca}

Menorca se localiza al noreste del archipiélago Balear, en el Mediterráneo Occidental. Tiene una extensión de $702 \mathrm{~km}^{2}$ y $216 \mathrm{~km}$ de costa. La distancia máxima entre dos puntos es de 47 km, entre Ciutadella y Maó. El punto más elevado tiene 357 m (el Toro).

Figura 1. Localización de Menorca

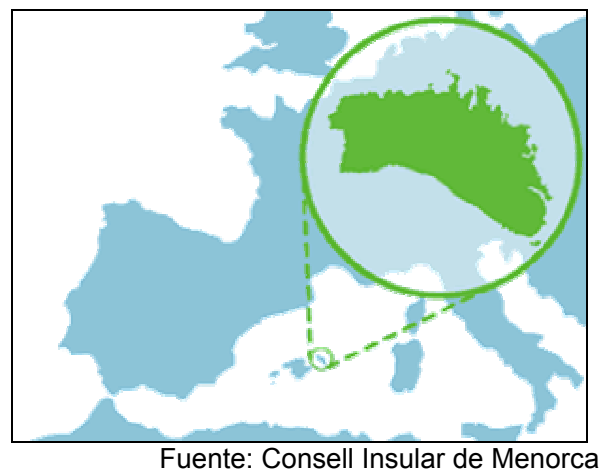

${ }^{2}$ Carreras et al., 2007. 
El paisaje menorquín está determinado por la climatología, típicamente mediterránea; la geología, calcárea y llana al sur y arcillosa y agreste al norte; y el viento de Tramontana, fresco y muy salino, que debido a la orografía relativamente llana de la isla sopla con fuerza y condiciona tanto la vegetación como muchos otros aspectos de la vida cotidiana. Estos condicionantes determinan un medio natural extraordinariamente diverso -dentro de un marcado carácter mediterráneo- con gran variedad de elementos florísticos. Debido a la localización de Menorca y su insularidad, abundan los taxones relictuales tirrénicos y baleáricos, destacando además la presencia de diversas especies endémicas de Menorca, localizadas en los acantilados costeros, los islotes y en los barrancos.

Económicamente, el sector dominante es el de servicios y el turismo. Con un desarrollo algo tardío (principalmente a partir de los años 80) Menorca no escapa de los problemas derivados del modelo turístico de "sol y playa", como la fuerte estacionalidad y la concentración de la demanda. Los alojamientos turísticos se localizan principalmente en el oeste y suroeste de la isla, con una predominancia de apartamentos frente a plazas hoteleras o viviendas unifamiliares. A pesar de esta predominancia del sector turístico, hay que destacar que, a diferencia de otras islas Baleares como Mallorca y Eivissa, Menorca conserva unos sectores primario y secundario de una relativa importancia, dedicados principalmente a la producción de queso, al sector del mueble y la bisutería.

Otro aspecto a destacar del territorio insular, y que condiciona las transformaciones y el desarrollo de este territorio, es la declaración de Menorca como Reserva de la Biosfera, que se produjo en el año 1993 dentro del programa MAB de la UNESCO como reconocimiento a la gran diversidad de sistemas naturales presentes en su reducido territorio, que abarcan prácticamente la totalidad de ecosistemas mediterráneos existentes. Esta distinción implica el compromiso de compatibilizar la actividad humana y la conservación del medio ambiente y la biodiversidad, es decir, avanzar hacia el desarrollo sostenible.

\subsection{Los municipios de Maó, Es Castell y Sant Lluís}

Los tres municipios que conforman la zona de estudio ocupan $163,76 \mathrm{~km}^{2}$ (el $23,58 \%$ del territorio de Menorca). La zona presenta una gran diversidad territorial, en primer lugar debido a sus características biogeográficas (substratos geológicos, masas de agua, etc.) y en segundo lugar a las diferentes figuras de ordenación territorial, que incluyen zonas protegidas como el Parque Natural de s'Albufera des Grau, zonas costeras con un gran desarrollo urbanístico, y la zona urbana y periurbana de la capital de Menorca, Maó.

Esta marcada diversidad se refleja también a nivel demográfico y socioeconómico. Estos tres municipios albergan el $47 \%$ de la población de Menorca (datos del 2003) y en el quinquenio 1998-2003 experimentaron un crecimiento medio del 18,9\%. Como se aprecia en la Tabla 1 los crecimientos poblacionales se repartieron de manera desigual:

Tabla 1. Población y crecimiento demográfico de los municipios de Maó, Es Castell y Sant Lluís (1998-2003)

\begin{tabular}{lcc}
\hline Municipio & Población en el 2003 & $\begin{array}{c}\text { Crecimiento en el período } \\
\mathbf{1 9 9 8 - 2 0 0 3}\end{array}$ \\
\hline Maó & 26.536 & $16,8 \%$ \\
Es Castell & 7.066 & $12,9 \%$ \\
Sant Lluís & 5.407 & $27,0 \%$ \\
\hline
\end{tabular}

Fuente: adaptación de Méndez, A., 2004. 
Los tres municipios de la zona de estudio son, por otro lado, los que más población extranjera tienen empadronada (15,2\% en Es Castell, $14,9 \%$ en Sant Lluís y 13,6\% en Maó) sólo superados por el municipio de Es Mercadal. La nacionalidad más frecuente entre la población de origen extranjero es la inglesa, seguida de la ecuatoriana y la marroquí. Estos datos tienen una correspondencia en el mercado de trabajo, que concentra casi un $50 \%$ de los afiliados de la Seguridad Social en la zona de estudio.

Finalmente, cabe mencionar la distribución de plazas turísticas en estos tres municipios, que suponen el $18,2 \%$ del total de Menorca, pero se concentran principalmente en Sant Lluís, con 5.807 plazas, seguido de Maó con 1.838 plazas y es Castell, con 1.232.

\section{Evaluación del Levante de Menorca}

\subsection{Evaluación de los aspectos naturales y paisajísticos del territorio}

El análisis de la cartografía digital ha permitido evaluar en detalle las características de las cubiertas naturales. Los aspectos que se han evaluado son:

1. Ocupación del territorio y cubiertas del suelo.

2. Estructura y diversidad del paisaje.

3. Conectividad, conectancia y fragmentación del territorio.

El análisis de las cubiertas del suelo refleja que el Levante de Menorca conserva un buen equilibrio entre las cubiertas "humanizadas" (11,3\%), "naturales" $(47,7 \%)$ y "agrícolas" $(40 \%)$. Sin embargo, una parte considerable del suelo agrícola se encuentra abandonado o dedicado al pastoreo, y por tanto puede estimarse que en un futuro próximo este suelo será colonizado por especies vegetales oportunistas. En los tres municipios este suelo "poco productivo" varía del 17 al $34 \%$. Mientras que en los municipios de Es Castell y Sant Lluís los campos abandonados se concentran alrededor de las zonas urbanizadas, en Maó, aunque también se observa este proceso, se aprecia una mayor concentración en la zona suroccidental del municipio.

Respecto a las cubiertas "naturales" se observa una presencia importante de vegetación de alto valor ecológico (26\%), localizado principalmente en las zonas costeras y en los encinares del centro y norte de Maó, y valor ecológico medio $(50 \%)^{3}$. En la Figura 2 se puede apreciar la distribución porcentual de los diferentes tipos de cubiertas del suelo:

3 Se han clasificado las cubiertas vegetales en cubiertas de "alto valor ecológico", "valor ecológico medio", y "bajo valor ecológico" según las directrices de la Directiva Hábitats (Directiva 92/43/EEC, de 21 de mayo, relativa a la

Conservación de los Hábitats Naturales y de la Fauna y la Flora Silvestres) y las consideraciones recogidas durante la elaboración de la cartografía digital de Usos y Cubiertas del Suelo. Para establecer las correspondencias entre la Directiva Hábitats y la clasificación CORINE se ha utilizado el sistema de referencias cruzadas EUNIS (Moss, Davies, 2002), si bien debe tenerse en cuenta que en ocasiones no existe una correspondencia exacta entre ellas. 
Figura 2. Ocupación de cubiertas del suelo en el Levante menorquín

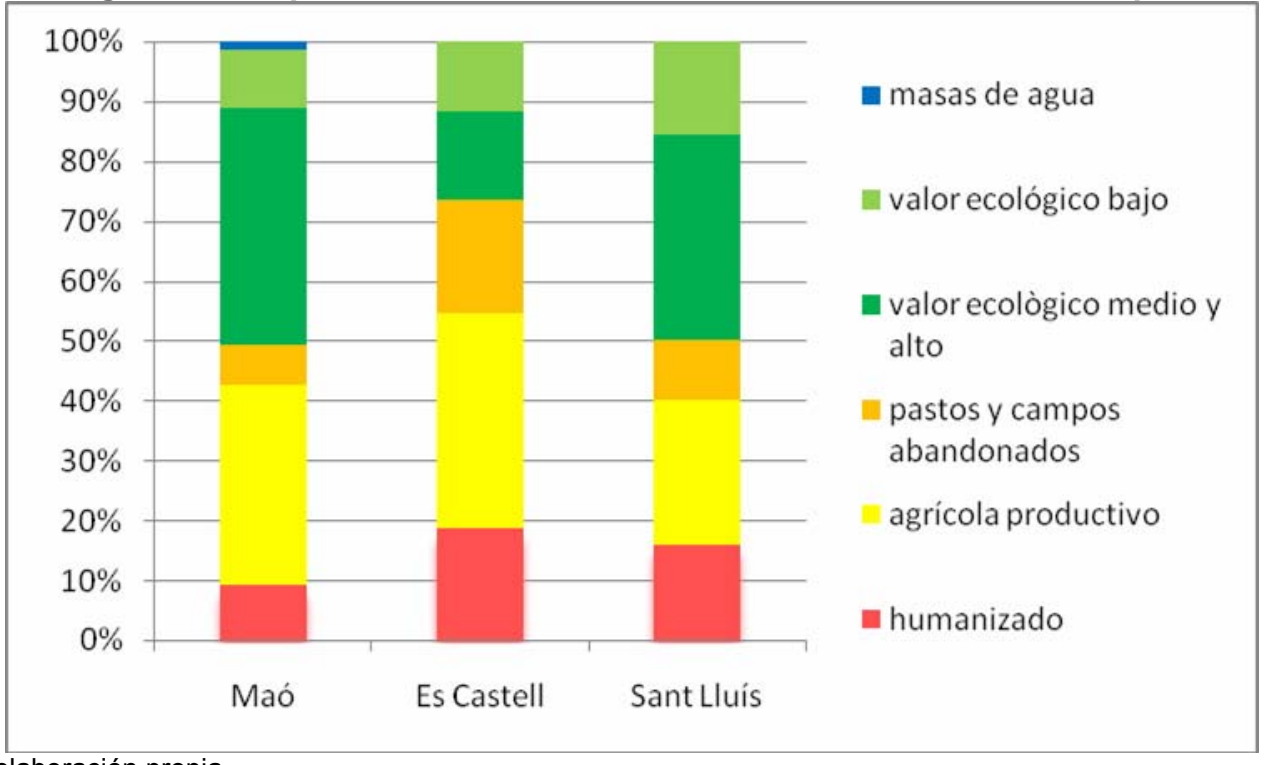

Fuente: elaboración propia

Se puede observar como existe una relación entre el suelo agrícola abandonado y el suelo humanizado, y a su vez entre estas dos categorías y el porcentaje de vegetación de valor ecológico bajo. Esto se explicaría como la consecuencia de la pérdida de equilibrio entre los tres ecosistemas, que en Menorca han evolucionado hasta resultar interdependientes. La degradación de los sistemas agrícolas afectaría negativamente los sistemas naturales colindantes, de la misma manera que las grandes infraestructuras o núcleos de población contribuyen a degradar el entorno natural cercano. A su vez, la mayor presión urbanística favorecería el abandono de los usos agrícolas a favor de otros con un mayor rendimiento económico.

En relación a la estructura del paisaje, se han analizado los principales parámetros de la matrix, patches y corridors (matriz, celdas y corredores) propuestos por Forman \& Gordon ${ }^{4}$ y también los principales parámetros del territorio en su conjunto (ver Tabla 2). El resultado de estos análisis muestra un territorio de diversidad media-alta, con los diferentes elementos del paisaje en equilibrio en relación a su ocupación del territorio. En cambio se aprecia un tamaño de grano relativamente pequeño y un elevado nivel de fragmentación del territorio. 
Tabla 2. Principales características estructurales del paisaje

\begin{tabular}{|c|c|c|}
\hline Parámetro & Resultado & Descripción \\
\hline Área total & 16.375 ha & $\begin{array}{l}\text { Superficie total de los municipios de Maó, Es Castell y } \\
\text { Sant Lluís }\end{array}$ \\
\hline Número de clases & 11 & $\begin{array}{l}\text { Número de elementos del paisaje que se han } \\
\text { diferenciado en el territorio }\end{array}$ \\
\hline Numero de celdas & 26.633 & Número total de polígonos en el territorio estudiado \\
\hline $\begin{array}{l}\text { Diversidad (Índice de } \\
\text { Shannon-Wienner) }\end{array}$ & 0,6832 & $\begin{array}{l}\text { Medida como } \mathrm{H}=-\sum \mathrm{pi} \cdot \log (\mathrm{pi}) \text {, donde pi corresponde al } \\
\text { porcentaje en superficie de cada elemento del paisaje }\end{array}$ \\
\hline Dominancia & 0,3439 & $\begin{array}{l}\text { Medida como } \mathrm{D}=\left[\mathrm{Hmax}+\sum \mathrm{pi} \cdot \log (\mathrm{pi})\right] / \mathrm{H} \text {, donde } \mathrm{Hmax} \\
\text { es igual al logaritmo del número total de elementos del } \\
\text { paisaje }\end{array}$ \\
\hline Fragmentación & 2.421 & $\begin{array}{l}\text { Se calcula como el número total de polígonos dividido } \\
\text { por el número de elementos diferenciados }\end{array}$ \\
\hline Tamaño de grano & $7.214 \mathrm{~m}^{2}$ & $\begin{array}{l}\text { Media del área de los polígonos presentes en el } \\
\text { territorio }\end{array}$ \\
\hline
\end{tabular}

Fuente: elaboración propia a partir de Pino \& Rodà, 1999.

Para el análisis de la conectividad se han clasificado las cubiertas presentes en la zona de estudio como "favorables", "desfavorables", "barreras" y "zonas de paso" y se ha realizado un análisis cuantitativo y cualitativo de la cartografía resultante. Se pueden apreciar diferencias notables entre la zona norte y la zona sur: mientras que al norte de la bahía de Maó existe una buena conectancia ${ }^{5}$ entre zonas favorables y conectoras, los espacios protegidos se encuentran en general bien conectados y el tamaño de los polígonos favorables es relativamente grande (media de $6.885 \mathrm{~m}^{2}$ ), al sur se observan problemas de conectividad acusados. A la ausencia casi absoluta de conectores hay que añadir la presencia de "zonas desfavorables" y barreras dispersas en el territorio, así como un tamaño mediano de las "zonas favorables" mucho menor (media de $1.882 \mathrm{~m}^{2}$ ).

\subsection{Evaluación de los aspectos antrópicos del territorio}

El análisis de la cartografía digital de usos del suelo se ha centrado en las cubiertas urbanas o humanizadas por ser las que presentan mayor diversidad. El dato más destacable de este análisis es sin duda la predominancia de usos turísticos o de segunda residencia frente a la primera residencia. La presencia en el territorio de los dos primeros $(328,6$ ha) triplica la presencia de núcleos de población (130,3 ha). Este fenómeno es especialmente acusado en el municipio de Sant Lluís, donde la ocupación de segundas residencias $(11,9 \%)$ o residencias turísticas $(28,7 \%)$ es más de diez veces superior a la ocupación de primeras residencias $(3,5 \%)$. Otro dato que cabe destacar es la concentración del suelo dedicado a equipamientos e infraestructuras en Maó, en parte justificada por su mayor población y su condición de capital de la isla.

Las infraestructuras de comunicación juegan un papel decisivo en la localización de las segundas residencias y otros usos propios de la periferia urbana, tales como zonas industriales, comerciales y equipamientos. Estos elementos se localizan bordeando el eje de

5 La conectancia indica la presencia de límites comunes entre los diferentes elementos del paisaje. Es una medida de adyacencia o de "conexión física" del territorio. 
las principales vías de comunicación y configuran las denominadas áreas de influencia de los núcleos urbanos.

Las áreas de influencia presentan características singulares desde el punto de vista territorial, ya que a pesar de que no resultan en general tan impermeables para la mayoría de especies de flora y fauna como los núcleos urbanos, constituyen en muchas ocasiones territorios degradados $\mathrm{o}$ en proceso de degradación, con abundancia de especies oportunistas y elementos artificializadores. Para el cálculo de las áreas de influencia de los núcleos urbanos se han seleccionado todos los usos claramente dependientes de estos (usos industriales o comerciales, equipamientos, parcelas con uso recreativo) conjuntamente con los mismos núcleos urbanos y los núcleos turísticos y se ha realizado un buffer de $50 \mathrm{~m}$. De los polígonos resultantes, se han seleccionado tan solo los mayores de 7 ha, por considerarse que tienen un tamaño suficiente para suponer una perturbación en la estructura del territorio. En la Figura 3 se muestra un detalle de los principales núcleos urbanos del Levante de Menorca y sus áreas de influencia.

Figura 3. Detalle de los núcleos urbanos y sus áreas de influencia

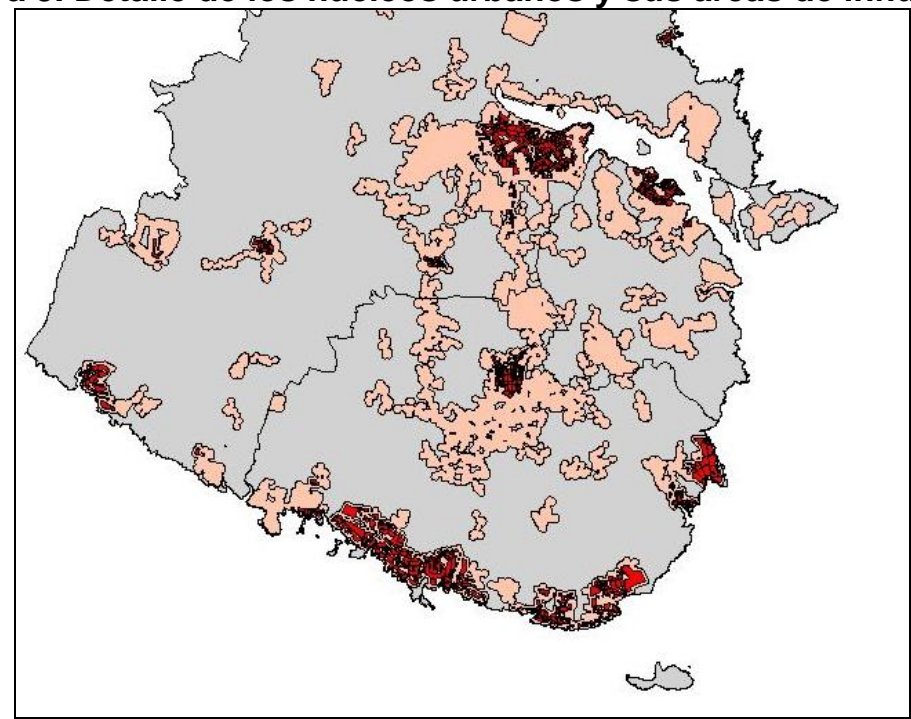

Fuente: elaboración propia

Las áreas de influencia de los núcleos de Maó, Es Castell y Sant Lluís llegan a ser 14, 20 y 8 veces mayores que el propio núcleo, respectivamente. La morfología que adoptan es la de "mancha de aceite" con extremos alargados siguiendo las vías de comunicación principales. En cambio, las áreas de influencia de los núcleos turísticos forman un cinturón de forma más o menos circular a su alrededor. Aunque a priori puede parecer que el área de influencia de los núcleos urbanos es proporcionalmente mayor que la de los núcleos turísticos, debe tenerse en cuenta que estos últimos presentan en general una densidad mucho más baja que los primeros. Finalmente, cabe destacar que en ocasiones las áreas de influencia forman "anillos" que unen dos núcleos urbanos (como por ejemplo el formado entre los de Maó y Sant Lluís) que -sin llegar a formar un continuo urbano- conforman cinturones semi-urbanizados de baja densidad, en cuyo interior se encuentran con frecuencia espacios degradados.

Respecto a la distribución de los impactos entre la costa y el interior, se observan dos procesos muy diferenciados: 
- En la costa los impactos se deben a la urbanización del territorio, que en la zona de estudio presenta una de las mayores densidades de la isla. Si bien estos impactos son muy importantes, se encuentran concentrados en determinados puntos, ya que la normativa protege actualmente la práctica totalidad del litoral no urbanizado.

- La protección de la costa está provocando que las nuevas edificaciones se desplacen al medio rural. La presión difusa ejercida por segundas residencias y infraestructuras conllevan impactos como la reducción del tamaño de las parcelas y la bajada de la productividad agrícola, la banalización del paisaje, la degradación de los ecosistemas y, en general, la pérdida de la dinámica agrícola.

\section{Relación de la diagnosis con el Plan Territorial Insular de Menorca}

\subsection{Clasificación del suelo según el PTI}

EI PTI se aprobó en el 2003 después de 3 años de trabajos previos, en los que los procesos de participación ciudadana gozaron de un papel destacado. Un amplio consenso en casi todo los sectores sociales de Menorca en limitar el crecimiento urbanístico y turístico de la isla -fruto de la aceptación del hecho de que la capacidad de carga en aspectos como el consumo de agua, energía, conservación de la biodiversidad, etc. se habían superado- permitió desarrollar el PTI alrededor de cuatro ejes principales ${ }^{6}$ :

- Protección activa de los recursos naturales y del paisaje.

- Desarrollo urbano basado en la utilización prudente del territorio.

- Transformación cualitativa del turismo basado en la gestión creativa de los recursos naturales.

- Agricultura sostenible y diversificada como garantía de la preservación de los recursos naturales y del paisaje rural.

El desarrollo de estos ejes se concreta mediante la definición de diferentes categorías de suelo y su delimitación (ver Tabla 3), para cada una de las cuales el PTI fija condiciones estrictas de edificación, usos, posibles clasificaciones en los planeamientos municipales, requerimientos ambientales, etc. que buscan preservar los valores propios de la zona y protegerlos frente a sus principales amenazas. 
Tabla 3. Categorías de clasificación del suelo según el PTI

\begin{tabular}{ll} 
Categoría & Subcategorías \\
\hline Equipamientos & Incluye puertos, aeropuertos, etc. \\
\hline Suelo Urbano y Urbanizable & Suelo Urbanizable \\
& Suelo Urbanizable Programado \\
& Suelo Urbanizable no Programado \\
& Área de Reconversión Territorial: incluye la previsión de \\
& suelo destinado a zona verde o Espacio Libre para las zonas \\
& de esponjamiento \\
\hline Suelo Rústico Común & Áreas de Interés Agrario \\
& Áreas de Transición \\
& $\begin{array}{l}\text { Núcleos Rurales } \\
\text { "Horts d'oci" (parcelas de uso recreativo o de segunda } \\
\text { residencia) }\end{array}$ \\
\hline Suelo Rústico de Especial & Figuras de protección (Parque Natural, ANEls, ARIPs) \\
Protección & Áreas de Alto Nivel de Protección (franja de 100 m de costa, \\
& sistemas dunares, humedales, encinares, etc.) \\
& Áreas Naturales de Interés Territorial \\
& Áreas de Interés Paisajístico \\
& Áreas de Prevención de Riesgos \\
& Áreas de Protección Territorial \\
\hline
\end{tabular}

Fuente: elaboración propia a partir de las Normas de Ordenación Territorial Insular

En la Figura 4 se puede observar la cartografía básica del PTI. 


\section{Figura 4. Cartografía básica del Plan Territorial Insular de Menorca}

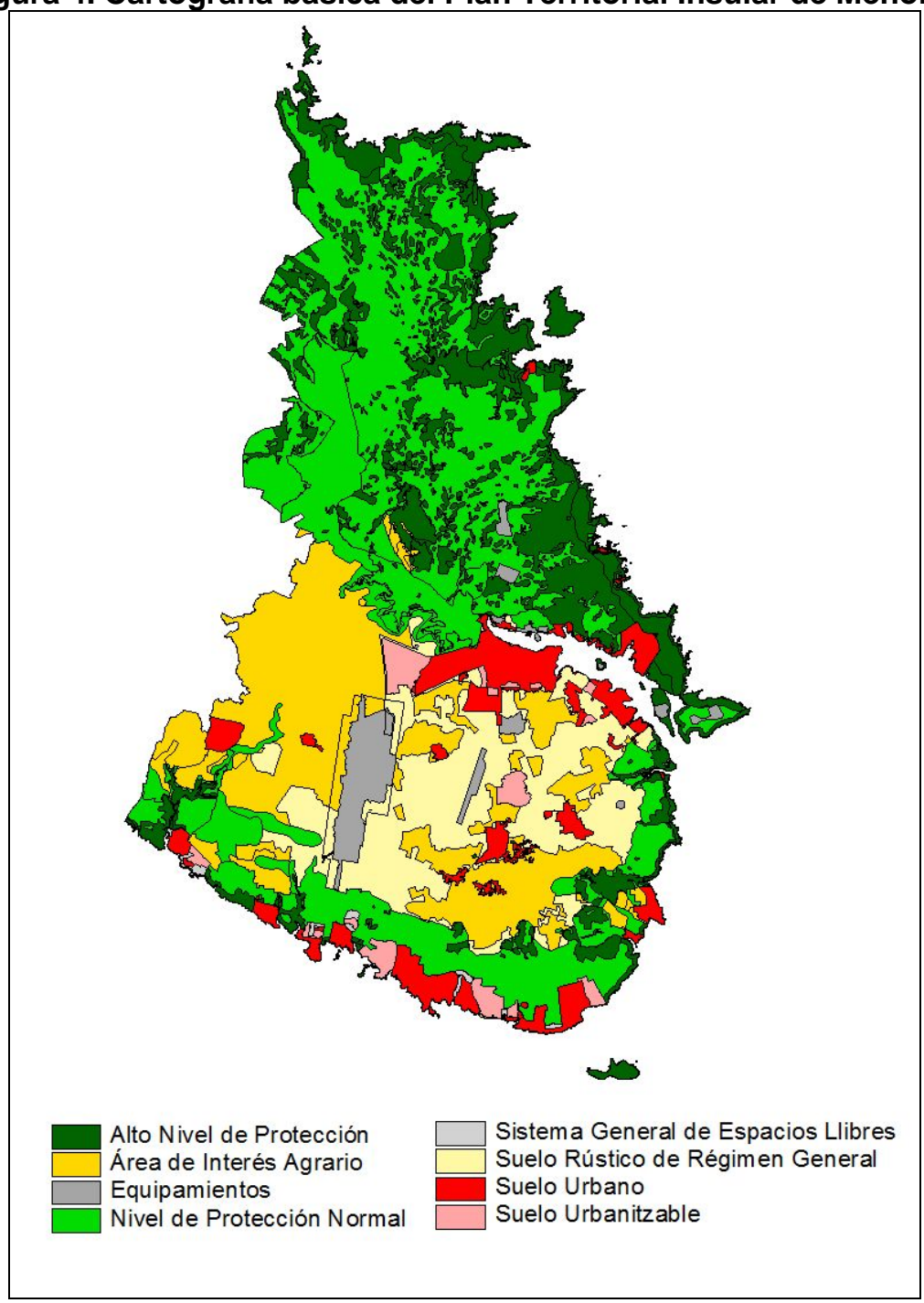

Fuente: Plan Territorial Insular de Menorca

4.2 Comparación de la cartografía del PTI con la cartografía de Usos y Cubiertas del Suelo

La comparación de la clasificación general del suelo según la cartografía del PTI (de aplicación obligatoria según la normativa del PTI) se ha cruzado con la clasificación de cubiertas del suelo descrita en el apartado 3.1 (cubiertas "naturales", "agrícolas" y "humanizadas"). Las correspondencias obtenidas son las siguientes: 
Tabla 4. Comparación de las categorías de suelo del PTI con la cartografía de Usos y Cubiertas del Suelo

\begin{tabular}{lll}
$\begin{array}{l}\text { Categoría de suelo } \\
\text { según el PTI }\end{array}$ & $\begin{array}{l}\text { Categoría de suelo } \\
\text { según clasificación } \\
\text { cubiertas }\end{array}$ & Observaciones \\
\hline
\end{tabular}

Equipamientos

Humanizado

Urbano

Humanizado

Urbanizable

Natural, Agrícola y

Humanizado

Área de Reconversión

Territorial

Suelo Rústico común

Áreas de Interés Agrario

Agrícola

Suelo Rústico de Especial Protección

Agrícola y Natural

Natural

Agrícola y Natural
Se corresponde más específicamente con la categoría de Usos del Suelo "equipamientos" aunque sólo considera los de dimensiones mayores.

Se corresponde casi completamente con la categoría "núcleo urbano" de la cartografía de Cubiertas, con la excepción del nuevo polígono industrial de Sant Lluís, que en la cartografía del PTI se prevé "urbanizable". Además, en algunos polígonos de la zona sur de Sant Lluís se recogen como "urbanos" algunos polígonos de vegetación natural.

Las zonas declaradas urbanizables corresponden mayoritariamente a las zonas agrícolas y zonas naturales de valor ecológico medio y bajo. En algunas parcelas existían anteriormente algunas edificaciones dispersas y en otras ya se ha avanzado en el proceso de urbanización desde la aprobación del PTI.

Natural y Humanizado Existen 6 polígonos declarados de Reconversión Territorial que corresponden a áreas humanizadas degradadas (vertederos, áreas marginales) y a zonas de vegetación de valor ecológico medio y alto.

Mayoritariamente se corresponde con suelo agrícola, pero también se encuentran extensiones

relativamente grandes de vegetación, principalmente de acebuche y acebuche en regeneración.

Corresponde mayoritariamente a cubiertas agrícolas.

Corresponde a cubiertas agrícolas y cubiertas naturales de valor ecológico medio y alto.

Comprende las zonas costeras y las zonas ANEI.

Comprende la mayor parte de cubiertas naturales con un alto valor ecológico.

Areas de A
Protección

Fuente: elaboración propia 


\subsection{Comparación de las propuestas del PTI con las conclusiones de la evaluación de cubiertas del suelo}

La clasificación del suelo en el PTI tiene, como se ha visto en el apartado anterior, cierta correspondencia con las cubiertas del suelo, pero se observa también la influencia de otros parámetros en la delimitación de los polígonos:

- La clasificación de suelo urbanizable se ha definido buscando la continuidad urbana entre zonas ya construidas y la máxima proximidad a las vías de comunicación.

- Las Áreas de Interés Agrario se han definido de manera que a menudo delimitan las áreas urbanas y urbanizables, con la intención de proteger estas áreas de la degradación a que se ven sometidas las áreas contiguas a los núcleos urbanos.

- El Suelo Rústico General conforma una matriz entre los tres núcleos de población principales y el aeropuerto, así como otras zonas urbanas no costeras, donde previsiblemente se localizaran actividades y usos con un mayor impacto sobre el medio ambiente.

El suelo agrícola de la zona de estudio se encuentra mayoritariamente clasificado dentro de las categorías de Suelo Rústico Común (y especialmente dentro de la subcategoría Área de Interés Agrario) y en la categoría de Suelo Rústico de Especial Protección. Mientras que en la primera se permiten ciertos usos como la ganadería y la agricultura no profesional, así como la regularización de segundas residencias ya existentes, en la segunda la normativa es mucho más estricta, y tiene como finalidad principal conservar los valores naturales, paisajísticos y territoriales que poseen. Para la subcategoría de Área de Interés Agrario la normativa permite solamente la explotación profesional del terreno, y las edificaciones y infraestructuras relacionadas, evitando así que parcelas agrícolas se transformen en segundas residencias 0 zonas de uso recreativo. En muchos casos, esta figura se utiliza para restringir la expansión de zonas residenciales o periurbanas. La excepción, sin embargo, la encontramos en el núcleo de Trebalúger, rodeada de Suelo Rústico Común, y las segundas residencias que bordean el camino del sur de Llucmaçanes, no reconocidas como núcleo urbano y rodeadas también de Suelo Rústico Común.

Las cubiertas naturales están comprendidas mayoritariamente dentro de las categorías de Suelo Rústico Común, Suelo Rústico de Especial Protección y, especialmente, en la subcategoría de Alto Nivel de Protección. Mientras que en las dos primeras se permiten e incluso se favorecen las actividades agrícolas -aunque con algunas restricciones en el segundo caso- en las zonas de Alto Nivel de Protección se prioriza la conservación de los valores naturales de la vegetación. Esta clasificación tiene una clara correspondencia en la distribución de las especies vegetales presentes en el territorio: en las zonas de Suelo Rústico Común encontramos principalmente bosques de acebuche y acebuche en regeneración, como también maquia esclerófila y pinares, En el Suelo Rústico de Especial Protección se encuentran también estas especies en menor medida, y otras como matorral de brezos y jaras, bosques mixtos de encinas y pinos, etc. En las Zonas de Alto Nivel de Protección se encuentran casi exclusivamente especies de alto valor ecológico, como encinares, vegetación propia de las zonas costeras, etc. Sin embargo, algunas zonas con vegetación de alto valor ecológico se encuentran fuera de ninguna figura de protección (ver Figura 5)

Respecto a la conectividad del territorio, el PTI prevé una continuidad entre dos zonas claramente diferenciadas: 
1. La zona norte, que comprende el Parque Natural de s'Albufera des Grau, zonas ANEI, etc.

2. La segunda línea del litoral sur de la zona de estudio.

En los dos casos encontramos las zonas de Alto Nivel de Protección unidas por zonas de protección normal que actuarían como zonas conectoras. Estas se corresponden generalmente con las zonas clasificadas como "favorables" en el análisis de la cartografía de cubiertas del suelo (ver apartado 3.1). Sin embargo, en la zona sur, donde la conectividad es más frágil, se han dejado fuera de estas figuras de protección algunas zonas "favorables" que podrían resultar de vital importancia (ver Figura 6). También cabe observar que la conectividad entre las áreas protegidas de la zona norte y la zona sur es prácticamente nula, con ausencia de zonas favorables o conectores y con la presencia de una red de carreteras y elementos humanizados que la dificultan. Solamente en la zona suroeste existe una posible vía de conexión, siguiendo el torrente de Canutells y continuando por el área de Interés Agrario que lo une con la zona norte.

Las áreas urbanas y urbanizables se encuentran delimitadas en el PTI de acuerdo con un proyecto de crecimiento sostenible y harmónico, incorporando conceptos como la capacidad de carga. Se prevén crecimientos y tipologías de vivienda y equipamientos diferenciados según la clasificación como núcleo turístico o núcleo tradicional, pero en ambos casos se prioriza la rehabilitación de suelos degradados por encima de la nueva ocupación de suelo y, en cualquier caso, los crecimientos deben formar un continuo urbano con la urbanización existente. Consecuentemente a estas directrices, el Suelo Urbanizable previsto en el PTI no sobrepasa en prácticamente ningún caso las áreas de influencia urbanas actuales, localizándose en las zonas marginales o de urbanización más dispersa para rellenarlas o unirlas con el núcleo urbano.

\section{Aportaciones y propuestas}

Después del análisis realizado de la realidad territorial del Levante de Menorca, en base a la cartografía digital de Usos y Cubiertas del Suelo 2002, los resultados (especialmente la cartografía digital generada) se han comparado con las directrices del PTI para este territorio. Fruto de esta comparación, se formulan algunas propuestas de mejora:

1. Clasificar como Área de Interés Agrario los campos que rodean el núcleo de Trebalúger. Esta figura de protección especialmente enfocada a los suelos agrícolas aseguraría la contención del crecimiento urbano y evitaría la degradación del área periurbana.

2. Clasificar como Áreas de Alto Nivel de Protección las zonas resaltadas en rojo en la Figura 5 (que corresponden a las zonas con vegetación de alto valor ecológico y que no se encuentran protegidas por ninguna de las figuras previstas en el PTI), en especial aquellas que actualmente están clasificadas como Suelo Urbano o Suelo Urbanizable. 
Figura 5. Zonas propuestas para ser clasificadas como Áreas de Alto Nivel de Protección

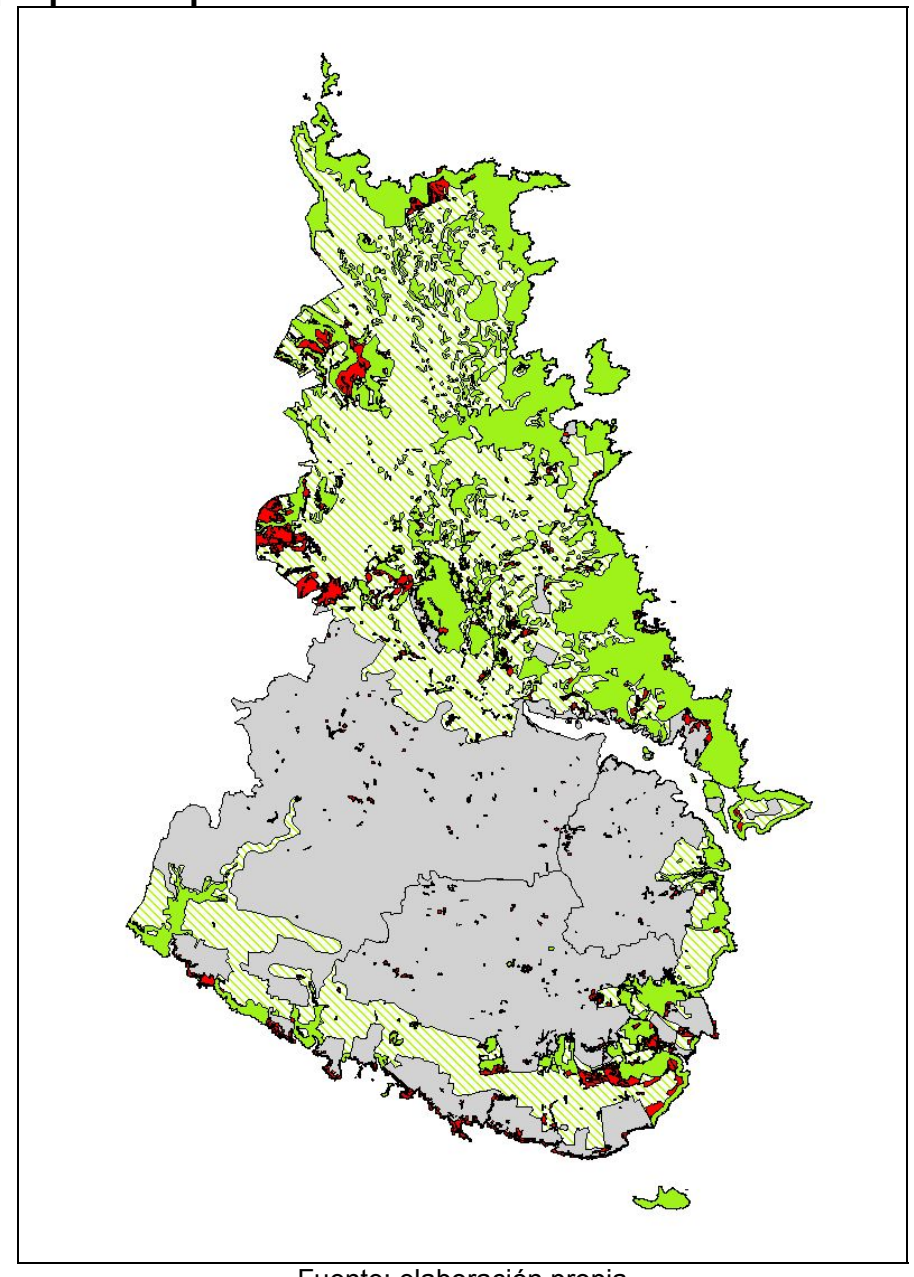

Fuente: elaboración propia

3. Clasificar las zonas resaltadas en naranja en la Figura 6 como Suelo Rústico de Especial Protección, especialmente aquellas que se encuentran adyacentes a las zonas actualmente protegidas. Estas zonas presentan un valor muy elevado des del punto de vista de la conectividad (zonas favorables y conectores) pero no están incluidas dentro de ninguna de las figuras de protección previstas en el PTI. 


\section{Figura 6. Zonas propuestas para ser clasificadas como Suelo Rústico de Especial} Protección

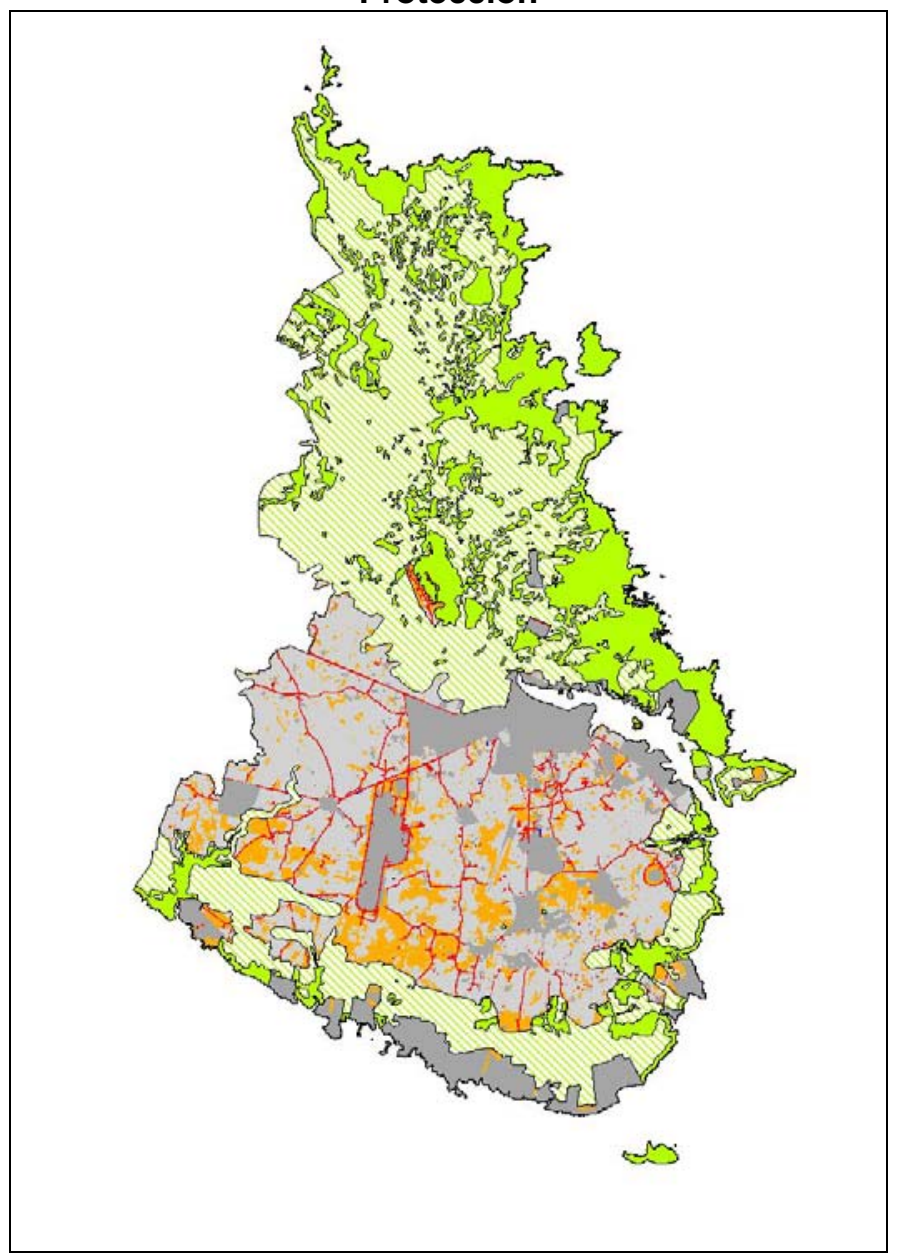

4. Establecer las medidas necesarias para asegurar la viabilidad de un corredor biológico entre las zonas protegidas del norte y del sur de la zona de estudio, ya que actualmente la conectividad entre estas zonas es prácticamente inexistente. Se estima que la zona más adecuada para constituir este corredor seria la indicada por el curso del torrente de Canutells.

5. Integrar, en la medida de lo posible, los usos de ocio, comerciales, equipamientos, $y$ todos aquellos que requieran los ciudadanos con regularidad, dentro del entramado urbano, con el fin de evitar desplazamientos innecesarios y reducir los impactos en el medio rural y natural.

6. Prever una especial protección frente a la urbanización dispersa y los impactos difusos en el suelo rústico colindante a las vías de comunicación, por ser esta la localización preferente donde, de manera espontanea, se localizan equipamientos, segundas residencias y otras edificaciones propias de a periferia de los núcleos urbanos. 


\section{Bibliografía.}

Consell Insular de Menorca. Pla Territorial Insular de Menorca. Menorca: CIME 2003.

Consejo Europeo. Directiva 92/43/EEC del Consejo, de 21 de mayo, relativa a la Conservación de los Hábitats Naturales y de la Fauna y la Flora Silvestres.

Carreras, David; Pons-Fàbregas, Catalina; Canals, Agnés. Cartografia Digital de l'Ocupació del Territori de Menorca - 2002. Memòria final del projecte. Institut Menorquí d'Estudis, 2007. Informe inédito.

Forman, R.T.T.; Gordon, M. Landscape ecology. New York: John Wiley \& Sons, 1986.

Mata, R. Desarrollo sostenible, insularidad y gobierno del territorio: la experiencia del PTI de Menorca. Boletín de la A.G.E., 2006, núm. 41, p. 183-198.

Méndez, A. Indicadors econòmics de Menorca 2004. Menorca. Institut Menorquí d'Estudis. 2004.

Moss, D.; Davies, C.E. European topic centre on nature protection and biodiversity. EUNIS Habitat Classification. 2001 work programme. Envionment Agency, 2002.

Pino, J.; Rodà, F. L'ecologia del paisatge: un nou marc de treball per a la ciència de la conservació. Butlletí de I'Institut Català d'Història Natural, 1999, núm. 67, p. 5-20. 